Portland State University

PDXScholar

Dissertations and Theses

Dissertations and Theses

1976

\title{
A Specialized Child Protective Service Unit
}

\author{
Paul O. Powers \\ Portland State University \\ Bonnie J. Vance \\ Portland State University
}

Follow this and additional works at: https://pdxscholar.library.pdx.edu/open_access_etds

Part of the Social Work Commons

Let us know how access to this document benefits you.

Recommended Citation

Powers, Paul O. and Vance, Bonnie J., "A Specialized Child Protective Service Unit" (1976). Dissertations and Theses. Paper 1812.

https://doi.org/10.15760/etd.1811

This Thesis is brought to you for free and open access. It has been accepted for inclusion in Dissertations and Theses by an authorized administrator of PDXScholar. Please contact us if we can make this document more accessible: pdxscholar@pdx.edu. 
AN ABSTRACT OF THE RESEARCH PRACTICUM OF Paul O. Powers and Bonnie J. Vance for the Master of Social Work presented May 28, 1976. Title: A Specialized Child Protective Service Unit APPROVED BY THE PRACTICUM ADVISOR2

Arthur Emlen

The purpose of the study was to provide a descriptive analysis of a specialized Child Protective Service unit's time and effort on case activities. The research sought to give an overview of what is involved in working with protective service cases, and examined the decision-making process in the provision of services. Finally, this process was related to casework effort and to outcomes.

To obtain a representative picture of what is involved in the management of a new case and of a caseload of protective service cases, two random samples were drawn (10 intake cases and 40 ongoing cases). The results:

- Services were directed toward maintaining children in their own home. This was demonstrated by

- 95 percent of the children from the intake group were in their own home at the end of the twelve weeks although 55 percent were outside of their own homes at the time of referral. 
- 84 percent of the children in the ongoing sample were residing in their own homes.

- Iow caseload size facilitates an early response to referrals. The average caseload was 23 cases per worker.

- Mre intensive service to families referred to protective services will reduce the number of children who must be placed in foster case, thereby reducing the cost of foster care payments by Children's Services Division.

- The unit serves long-tem cases to a major extent, contrary to manual guidelines. The study indicates that the clients served require continued service of the kind provided. 
A SPECIALIZED CHILD PROTECTIVE SERVICE UNIT

by

PAUL O. POWERS

and

BONNIE J. VANCE

A research practicum submitted in partial

fulfillment of the requirements for a degree of

MASTER OF SOCIAL WORK

Portland State University

1976 


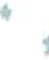

TO THE OFFICE OF GRADUATE STUDIES AND RESEARCH:

The practicum advisor approves the research report of $\underline{A}$ SPECIALIZED CHIID PROTECTIVE SERVICE UNIT by Paul O. Powers and Bonnie J. Vance presented May 28, 1976.

Arthur Emlen 


\section{ACKNOWLEDGEMENTSS}

We would like to acknowledge our appreciation and gratitude to Arthur Emlen, Professor, School of Social Work, and Director of the Regional Research Institute for Human Services, for serving as our research advisor; Dale Meiners, supervisor of the North Portland Branch Child Protective Service unit along with his staff who were so coperative; and Ada Wilson, Professor, School of Social Work, for her editorial assistance.

Paul O. Powers

Bonnie J. Vance

Portland, Oregon

May 28, 1976 
TABLE OF CONIENTS

PAGE

ACKNOWLEDGEMENTS. . . . . . . . . . . . . . $i$ ii IIST OF TABLES . . . . . . . . . . . . . . . V v IIST OF FIGURES ..................... . . vi

CHAPTER

I INTRDDUCTION ................. 1

II PROVISI@N OF CHIID PROTECTIVE SERVICFS AND THE ROLE OF THE SPECIALIZED UNIT .............. 4

III CHIID PROTECIIVE SERVICFS AND THE DECISION-MAKING

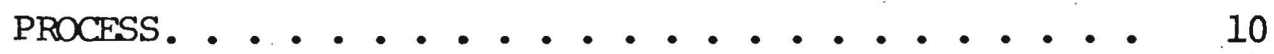

IV APPROACH AND METHOD. .............. 14

V FINDINGS ON INTAKE CASES ............ 21

VI FINDINGS ON ONGOING CASES. . . . . . . . . 31

VII CONCLLISIONS AND SUMMARY. . . . . . . . . 37

REFERENCES. ....................... 42

APPENDIX. . . . . . . . . . . . . . . . . 44 44 


\section{LIST OF TABLES}

TABLE

PAGE

I Location of Children Before and After Intake . . . . . 22

II Number of Days from Point of Referral to First Client

Contact. . . . . . . . . . . . . 23

III Location of Children in Ongoing Cases. . . . . . 32

IV Location of Children by Case in Ongoing Sample . . . . 33

V Duration of Ongoing Case Involvement . . . . . . . 34

VI Contacts and Time by Worker. . . . . . . . 34

VII Total Time Per Case Per Week (Collateral and Client

Contacts) . . • . . . . . . . . . 35 
LIST OF FIGURES

FIGURE

PAGE

1. Flow Chart for Protective Services ........ . 11

2 Distribution of Ongoing Cases. . . . . . . . 15

3 Intake Cases: Total Number of Hours Per Week with

Clients and collaterals (10 Cases) . . . . . 25

4 Intake Cases: Total Hours with Clients and Collaterals During 12 Weeks By Worker. . . . . . . . 26

5 Intake Cases: Number of Contacts with Clients and Collaterals (10 Cases) . . . . . . . . 27

6 Intake Cases: Total Number of Client and Collateral Contacts During 12 Weeks By Worker . . . . . . 29

7 Intake Cases: Time Length on Paper Work Over 12 Weeks (CSD and Court Related)......... 30 


\section{CHAPTER I}

\section{INTRODUCTION}

The North Portland Branch in Region 1 of the State of Oregon Children's Services Division had at the time of this study the only specialized Child Protective Service unit, where all protective service workers are under one supervisor, in that region. The supervisor and casework staff of the unit requested the study in the Spring of 1975. The purpose of the study was to provide a descriptive analysis of the unit's time and effort on case activities. Through this analysis the research sought to give an overview of what is involved in working with protective service cases and underscore the function of a specialized protective service unit. As part of this analysis an examination was made of the decision-making process in the provision of services. Finally, this process was related to casework effort and to outcomes.

The concept of a specialized Child Protective Service unit is one that has been considered by the Children's Services Division for the State of Oregon. In December 1974 the Oregon State Legislature had mandated that all local Children's Services Division offices establish specialized units for Child Protective Services. The purpose of protective services, as defined by Children's Services Division, is:

to insure the good health, sense of well-being and protection of any child who is physically or emotionally abused, neglected, exploited, and/or abandoned by his caretakers according to the community's 
minimum standards of child care. (Oregon CSD

Program Service Manual, November 1973)

The Program Manual defines the population appropriate for protective services as a child

whose parents fail, according to minimum community standards, to provide, either through their own efforts, or through the use of available community resources, the care, guidance, and protection a child requires for safety, healthy growth and development, and whose condition or situation gives observable evidence of the injurious effects of failure to meet, at least, his minimum needs. (Oregon CSD Program Service Manual, November 1973)

In the study, nine categories of abuse, neglect, or exploitation are considered. They are: 1) abandoned, 2) unattended/unsupervised, 3) inadequately supervised, 4) battered, 5) gross physical neglect, 6) situational neglect, 7) emotional abuse, 8) sexual abuse, and 9) educational neglect. These are further defined in Chapter IV. The rationale behind the need for specialized services is discussed in Chapter II.

These services are implemented in three phases: assessment, development of a social service plan, and provision of ongoing services. The program description as stated in the Oregon CSD Program Service Manual provides a stated goal for each. In the assessment phase, the goal is to respond to all requests for services and any report of abuse, neglect, exploitation, or abandonment. The goal in the development of a service plan is to identify the nature and causes of the abuse, neglect, exploitation, or abandonment; and develop ongoing services that would best alleviate the situation. In the ongoing services, the goal is to reduce and alleviate the occurrence of child abuse, neglect, exploitation, or abandonment; and to strengthen and enhance family life 
so that the child can have his needs met within his own home.

From the stated goals one would expect that emphasis is given to maintaining the family unit and indeed, the results of this study onfirm that family maintenance is the primary focus of the specialized unit.

To obtain a representative picture of what is involved in the management of a new case, and a caseload of protective service cases, two separate randam samples were drawn. The first sample was of 10 intake cases which included in their effort the assessment phase, and development of a social service plan. The second sample was of 40 ongoing cases which illustrated the activity involved in the provision of services. In combining the data from these two samples with the knowledge of the program and decision-making process, a general idea of just what is involved in a protective service caseload is achieved. 
CHAPIER II

\section{PROVISION OF CHILD PROTECTIVE SERVICES \\ AND THE ROLE OF THE SPECIALIZED UNIT}

The focus of this study has been a Child Protective Service unit offering a specialized service to families on whom a report of child neglect, abuse or exploitation has been made. Much has been written on the subject of special skills required of staff in child protection, and identifying it as an area of specialized service. The Child Welfare League published its standards for child protection in 1969, in which it identified such a service as a specialized child welfare service. It carries a delegated responsibility to offer help in behalf of any child considered or found to be neglected, abused or exploited. (CWLA, 1969)

Earlier social services for such children focused on investigation and adjudication of neglect, abuse or exploitation. There has been a decisive move away from this crime-and-punishment approach to a helping philosophy designed to protect the neglected, abused and exploited child, and help make parents more responsible. (DeFrancis, 1974) The focus is more toward helping these parents fulfill more adequately their parental role. Another important aspect of such service is toward social planning and action designed to identify and overcome conditions in the community which contribute to the problem. (CWLA, 1969)

The purpose of protective service to children is delineated in 
the following excerpt:

The service, in behalf of the child, has as its purpose to help parents recognize and remedy the conditions harmful to the child, and to fulfill their parental roles more adequately; or to initiate action, either with parental cooperation and consent or through petition to the court, to obtain substitute care for the child whose parents are unable, even with available help, to meet his minimum needs.

Protective service should also seek to identify and help overcome conditions in the community which contribute to or fail to avert neglect of children. It is not the purpose of a protective service to punish or prosecute parents. (CWLA, 1969)

In the provision of these specialized services there are unique characteristics which make them different from other child welfare services. These have been identified by several sources. (Gordon, 1946; Beck, 1955; Scherer, 1956; CWLA, 1969; Davoren, 1975) The request or referral for service is usually initiated from someone other than the parent or guardian in the form of a complaint of child neglect, abuse or exploitation. The parents may be hostile and resistive to any effort at intervention. The service has to be initiated by the agency in the best interests of the child, and involves reaching out with social services to the family. The protective service unit generally has a state mandate to provide service when needed, and an obligation to explore, study and evaluate the facts of the complaint and the effect on the children involved. Along with this is the obligation to continue services until the child is receiving proper care. If needed, protective service personnel have the responsibility to invoke the authority of the juvenile court when such an action is necessary to secure protection, 
care and treatment of the child if the parents or guardians are either unable or unwilling to provide for him.

Casework with the parents or guardian of the neglected, abused or exploited child is seen as the core of protective services. In working with these parents it is important to keep goals in mind. Four basic goals have been identified by the Standards for Child Protective Service. (CWIA, 1969)

1. The child should receive adequate care.

2. The parents should be able to fulfill their parental roles more adequately.

3. Unnecessary separation of the child from his parents should be prevented.

4. Whatever may be of value for the child in his relationship with his parents should be conserved.

As early as 1946, it was the observation of Henrietta Gordon that "the indiscriminate use of the term 'protective service' to include the wide variety of casework service for children impeded the development of specific professional skills and techniques which the distinctive characteristics of protective services makes necessary." (Gordon, 1946) The caseworker is expected to have, or to develop specific skills in order to provide the specialized service needed in child protection. (CWLA, 1969; DeFrancis, 1973; DeFrancis and Lucht, 1974; Davoren, 1975) The following is a summary of the skills identified by the cited sources.

1. Ability to communicate appropriately with parents who may be resistive and hostile towards intervention.

2. Ability to recognize when personal reactions may interfer with service to parents. 
3. Skill in motivating parents to change their care of their children.

4. Ability to involve appropriate supportive services necessary to ameliorate the conditions which led to the neglect, abuse or exploitation, i.e. homemaker, day care, financial, etc.

5. Enabling parents to accept the reality that neglect, abuse or exploitation does exist if in fact it does.

6. Ability to accept the parent where he is while at the same time not losing sight of the major responsibility which is adequate care and protection of the child.

7. Ability to evaluate and assess the extent of neglect, abuse or exploitation.

8. Ability to evaluate and assess the possible effect of separation of the child from the parents as opposed to continued care in the home.

9. Ability to evaluate evidence for court action in relation to the specific state statutes as applied to child abuse and neglect.

Protective service effort calls for a strong linkage between protective services and other community and welfare services. (Boehm, 1964) Part of the function of the specialized service is to identify the areas of stress in these families and coordinate the network of resources and services provided in the community for the alleviation of stress and prevention of further neglect, abuse and exploitation of children. The 
protection of children is not solely the function of a protective service unit but the worker has the role of acting as a broker of these services to the family.

A practical advantage of focusing efforts on protective service caseloads would be the prevention of unnecessary placement of children. Neglect, abuse or exploitation of a child by parents or guardians is the most frequent problem to come to the attention of child welfare agencies and constitutes a major reason for placement of children in foster care. (Jeter, 1963) It is Vincent DeFrancis' contention that a higher caliber of service, with greater competence and increased capacity for dealing. constructively with the problems presented by protective service cases, will inevitably reduce the number of children who must be separated from their homes. (DeFrancis, 1973)

Beck (1955) noted that the protective casework function should be identifiable as such and exercised by workers exclusively devoted to this most difficult task of helping. The advocacy of a specialized protective service unit is based on the thesis that the problems of child neglect, abuse and exploitation are acute and intricate and often involve long-standing psychosocial disturbances. Staff who work with such families must have training, experience and disposition to deal with the full range of difficult situations common to the protective service caseload. A national survey conducted in 1967 identified two prime requisites as imperative to an adequate child protective program. (American Humane Association, 1967) First, the program must recruit mature, experienced personnel with the highest social work skills. Secondly, caseloads must be tailored down and controlled to permit the application 
of those optimum skills in such intensive casework as individual cases may require. This same study found successful child protective programs holding caseload levels to between 20 and 25 active cases per worker.

The importance of caseload differentiation in child protective service to form a specialized caseload is closely related to what has been said about the purpose, goals, and unique characteristics of protective services. If one agrees to these and the thesis that special skills are required of protective service workers, it is logical to accept caseload differentiation as a legitimate means of achieving these concepts. The national survey of 1967 posited that by creating a protective service unit an agency accents the specialized focus of protective casework. (American Humane Association, 1967) By the establishment of such a unit, the effort and energy of specially skilled workers in protective services will not be diluted by general child welfare cases.

The approach to Child Protective Services presented here may be considered the classical model for the provision of these services. In 1974, Congress passed the Child Abuse Prevention and Treatment Act which authorized grants to the states and public and private agencies for demonstration programs concerned with child abuse and neglect. Most of the projects were funded for a three-year period. The programs were designed to test different strategies for handling the problem of child abuse and neglect. The results of these demonstration programs when published will no doubt provide new models for dealing with these problems. 
CHILD PROTECTIVE SERVICFS AND THE DECISION-MAKING PROCESS

It is inherent in protective services that the social worker is given major responsibility for decision-making. Throughout the period of service the social worker is confronted with critical decisions. Is the complaint valid? Should the child be removed from his home? Is court intervention required?

In view of this responsibility for decision-making, it is important to exanine the process of service delivery. Initially it should be stated that the social worker is not alone in the decision-making process for every decision is influenced by outside factors be they the community, the family, the child, another social agency, or statutory authority and the courts.

Boehm (1967) in her study of criteria for decision-making in protective services notes that the initial step rests with the commity. A request for service does not generally come from the family but is a result of community concern about mistreatment or inadequate care of a child. The first step in the process has been taken before the social worker via the agency enters the situation.

The Protective Service Program Manual for Children's Services Division provides a flow chart for protective services. Figure 1 illustrates four primary decision-making points in the protective services process. 


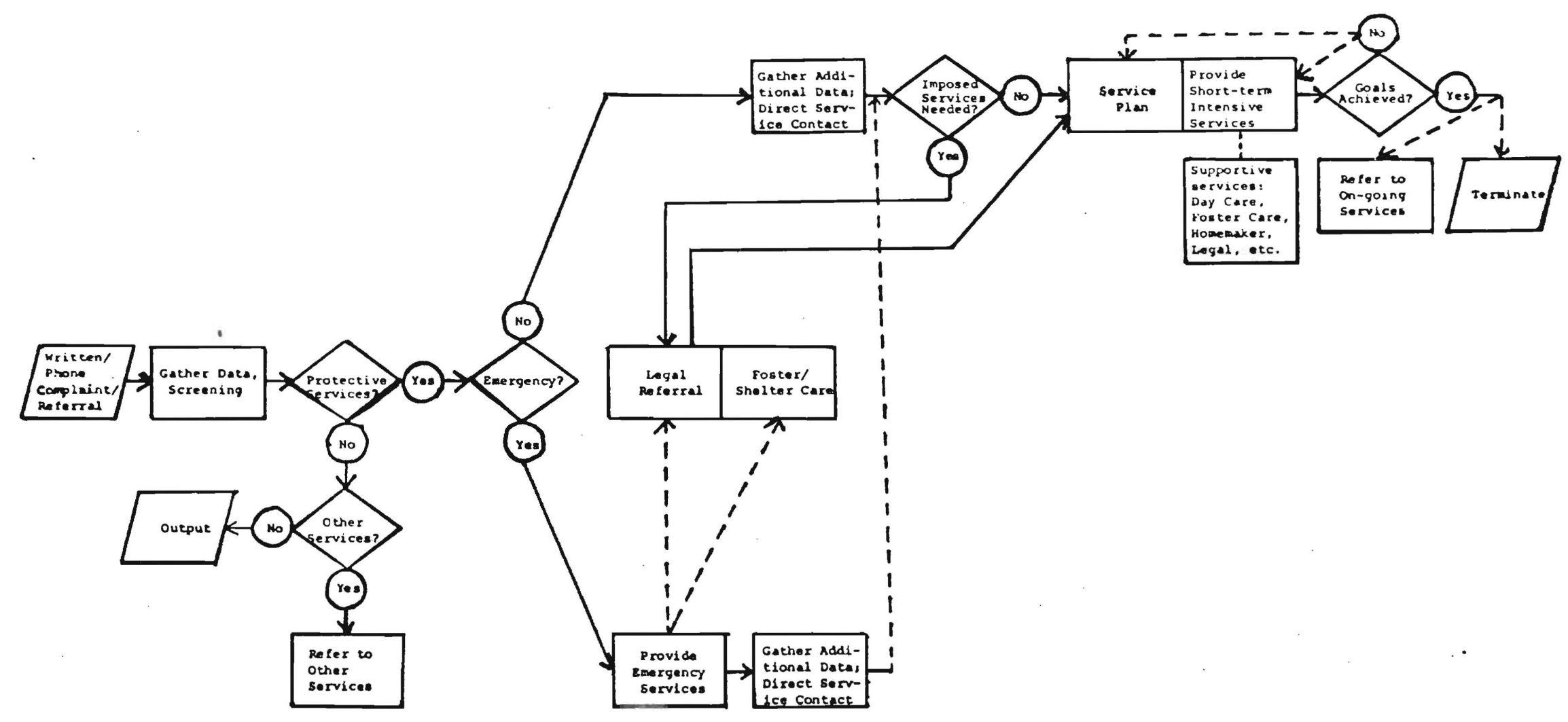

Figure 1: Flow Chart for Protective Services 
First, are protective services appropriate? Secondly, when the complaint is affirmed a determination must be made of whether an emergency condition exists. Thirdly, should protective services be imposed? Fourthly, have the treatment goals been achieved?

The flow chart represents Oregon Children's Services Division's conception of how the process should work. It is a guideline for the provision of services. The question is how adequate is the model? How aptly does the model describe the actual process?

While the chart demonstrates the general flow of services it does not necessarily identify the subordinate decisions. The primary decisions deal with the issue of intervention at different levels, and the subordinate, or secondary, decisions are related to the implementation of services. In the case of the first primary decision point when the referral is considered inappropriate a subordinate decision must be made. Should the case be referred to other services or closed? As indicated in Figure 1, in the event that the answer to the second and third primary decision points is "yes," this leads to consideration of legal intervention and possible placement. These are subordinate decisions which affect the determination of the service plan goals. There are multiple processes and decisions which potentially can be involved in developing and carrying out a service plan. Each service plan will vary according to circumstances. It is not within the scope of this study to illustrate the variety of combinations of decisions and processes. Rather, the aim is to present in a general way the flow of casework services to a family referred to Child Protective Services. Throughout the decision-making process there are numerous influ- 
ences such as the juvenile court and the guidelines set forth by the Children's Services Division which affect casework decisions made by the line worker. While the social worker has the direct responsibility for development and implementation of the service plan, he does not always have control over whether the plan will be followed through. Outside factors such as court intervention may supersede his authority. An example would be a court decision to remove a child from his home against the recommendations of the social worker. This example underscores what has been stated previously, that a protective service worker functions within the context of a larger system.

The process of decision-making is important when considering the data presented in this study. Two samples were taken, one of intake cases which focus on the first two primary decision points; the other, from the ongoing cases which involved the third and fourth primary decision points. The data demonstrate that during the intake phase more time and effort is involved in the initial phases compared with the provision of ongoing services. The inference is that during the period of time when important primary decisions must be made there is a greater expenditure of casework time and effort. 


\section{CHAPTER IV}

\section{APPROACH AND METHOD}

The study was in response to the Child Protective Service unit's request that we investigate how much time and effort goes into management of a new case, as well as into management of a caseload. Every caseload consists of two kinds of cases -- the new intake cases, and the ongoing cases. Two separate samples were drawn: 10 randomly selected intake cases each of which was followed for a twelve-week period; and 40 randomly selected ongoing cases which were followed for one week each. This sampling was designed to provide a representative sample of the effort typically required in handling new cases from the time they enter the unit for a period of twelve weeks, and secondly the effort required to manage a typical caseload in a Child Protective Service unit. Sample of Intake cases. In selecting new intake cases the decision was to consider the case new at the point that it was referred and assigned to the protective service unit, regardless of the referral source. Starting in July 1975 the five workers were instructed to follow the next 2 intake cases assigned to them. The total sample of intake cases was 10. Data were collected on each case for a twelve-week period following the date of referral.

Sample of Ongoing Cases. A list of cases on their caseload was obtained from each worker. From each list 2 cases per week were randomIy selected for a total of 8 cases per worker over a four-week period. The 10 intake cases selected for the study were not included in the pop- 
ulation of ongoing cases. As cases were selected from the lists they were not removed from the population. The total number of ongoing cases randomly selected was 40. Data were collected on each case for a period of one week. There were 10 cases each week, 2 per worker. The time period oovered was from mid-September 1975 to mid-October 1975. The following chart illustrates the distribution of cases:

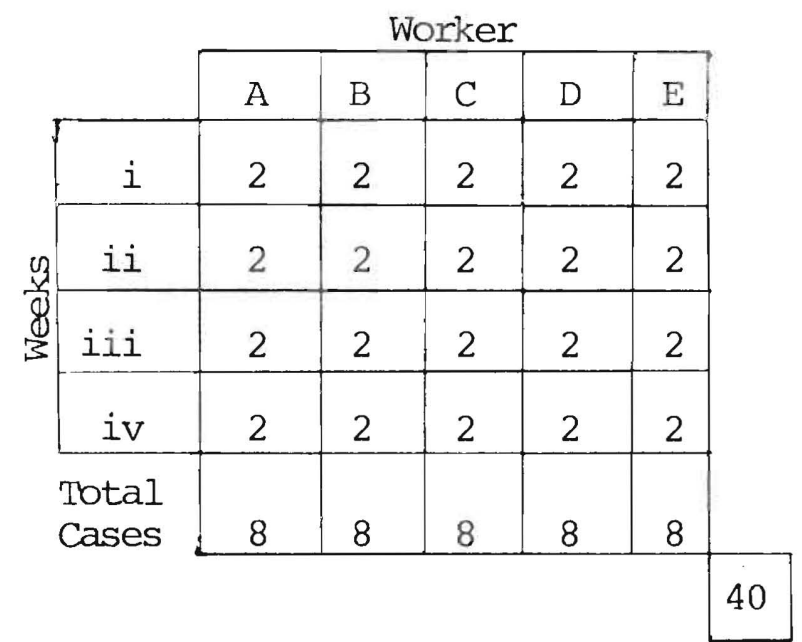

Figure 2. Distribution of Ongoing Cases.

Data Collection. In collecting data for both the intake and ongoing cases the instrument was standardized. See the Appendix for a sample of the form used. Descriptive information was obtained containing the various categories of information sought.

Ten categories of type of referral were considered. Following is a description of each category:

Abandoned: A child is considered to be abandoned when the parents have indicated their intent to no longer provide care for the child.

Unattended/Unsupervised: Unattended/unsupervised children are 
those who are alone for extended periods of time or whose whereabouts are unknown by the parents for extended periods of time. This classification differs from abandonment in that the parents intend to resume their care of the child.

Inadequately Supervised: Supervision is inadequate in cases in which the caretaker with whom the child is left does not possess the requisite skills for supervising or when the child is exposed to dangerous items or hazardous conditions in the home.

Battered (Physical Abuse): The child has sustained physical damage, such as bruises, lacerations, fractures or burns as a result of a nonaccidental physical act or acts. Gross Physical Neglect: The child has sustained physical or material deprivation, such as not being fed, clothed or bathed, which sometimes results in a physical state of ill health. Adequate medical care may be lacking. Situational Neglect: Situation in which a child receives minimm care and the parent(s) is known or suspected of having emotional problems and/or illness such as alooholism, drug addiction, mental illness, etc.

Emotional Abuse: The child has sustained emotional damage as shown by his behavior or is endangered as a result of various acts, such as being told repeatedly he is not "good" or by observing a parent or other child abused. Sexual Abuse: The following are examples of sexual abuse: rape, 
carnal knowledge, seduction, indecent liberties, exposure, incest, sodomy, solicitation, molestation.

Educational Neglect: Situation where the parent(s) refuses to send or allow their child to attend school.

Other: Any referral not covered by the above.

Fourteen separate referral sources were used to indicate the opening code on each case. The following were considered possible referral sources:

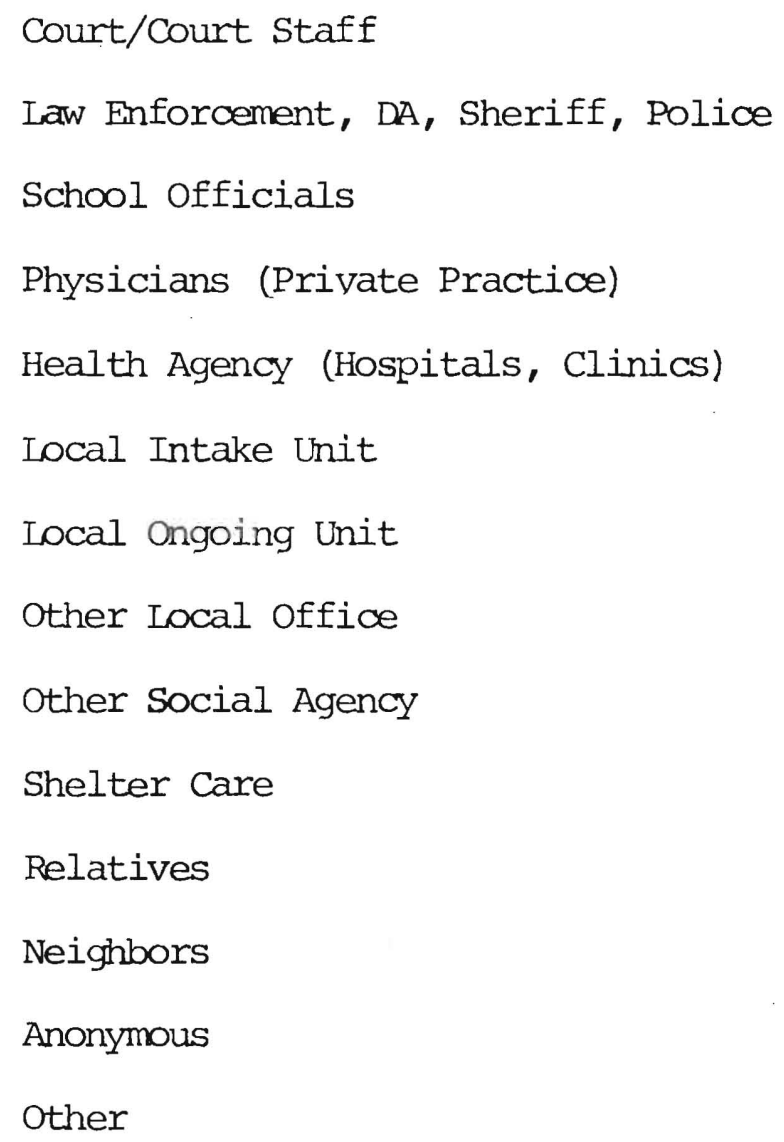

In the event that a case was terminated during the period of time data were being collected, a temination code was provided. There were nine possible reasons for termination:

No Abuse/Neglect Exists. 
Family Functioning with no Further Need for Protective Services or Other Services.

Family Functioning with no Further Need for Protective Services, Referred to Other Unit.

Family Functioning with no Further Need for Protective

Services, Referred to another Agency/Pro-

fessional for other service.

Child(ren) placed out of home, long-term, referred to ongoing Children's Worker.

Family Moved out of Local Office Jurisdiction, Case

Transferred.

Family Moved - Cannot be Located.

Family Refused to Cooperate, Referral to Juvenile Court not possible.

Other

The Project Effort Form (refer to the Appendix) was completed weekly by each worker on the cases which had been randomly selected. In order to detemine the type of effort and time involved, this form provided two main categories of contacts - client and collateral. Each of these was subdivided into more descriptive measures: office, field, travel time, phone, and paperwork. Paperwork was differentiated. Under client it was paperwork required by Children's Services Division, and for collateral, paperwork as related to the juvenile court. The workers were asked to indicate the date, and the amount of time on each effort. For the collateral contacts we asked that the agency/person contacted be listed. 
Pretest. A pretest of the Project Effort Form was conducted to determine the efficiency of the form, and the clarity of the instructions for its completion. From this pretest it was apparent that some minor revisions on the type of referral and sources were necessary. The form, otherwise, provided the necessary information we thought needed at that time for the study.

Problems - Intake Cases. Problems were enoountered in gathering data on the intake cases. We had neglected to find out the location of the child(ren) both at the point of referral and at the end of the twelve-week period. We were able later to retrieve this information from the case records.

In order to obtain an idea of the soope of activities involved on an intake case, we wanted to collect a full twelve weeks of data. If a case came into the unit and was terminated within a short period of time, one to three weeks, the worker was to substitute the next intake case assigned. Fortunately this only occurred in two instances.

At one point a worker already had one case to follow for the study, and then subsequently received 2 more new cases on the same day. Since only 2 intake cases per worker were to be followed, one had to be eliminated for purposes of the study. This was done by the toss of a coin.

Problems - Ongoing Cases. As on the intake cases, we also neglected to find out the location of the child(ren) for the ongoing cases. The location at the point of referral was not always apparent from the case record. Consequently we were only concerned with the location of the child(ren) at the time that data were collected on the case. 
This information was retrievable from the case record or the worker. The ongoing cases had been selected from the caseload of each worker. The random sample of cases was drawn at one time. It was probable that when the week came for a case to be followed that it may have been terminated. This was allowed for by the random selection of two altemative cases per worker. They were to be used as substitutes in the event that cases had been terminated. This substitution was necessary in three instances.

General Problems. There were some mutual problems encountered in data collection on both intake and ongoing cases. There were occasions when a caseaide was available to the unit to perform some of the tasks involved. Any effort and time which was spent by a caseaide was included in the count for the case involved. Attempted field contacts, and phone contacts by either a worker or caseaide were not counted, although the travel time was included. There had been some desire to also include consultation with the unit supervisor as a collateral contact. However, not all the workers recorded this, and it was consequently not included in the final analysis. If a worker had not given a length of time for a phone contact, it was estimated at 5 minutes. An estimation was made in one instance of travel time to, and length of collateral contact with the juvenile court. The travel time was estimated at $25 \mathrm{~min}-$ utes, and the length of collateral contact as 30 minutes. These estimations were made on the basis of other similar contacts. 


\section{CHAPTER V}

\section{FINDIINGS ON INTAKE CASES}

As indicated in Chapter IV part of this study was designed to provide a representative sample of how much time and effort goes into management of a new case. This chapter reports the descriptive findings, and an analysis of the time and effort involved in the 10 sample intake cases over a twelve-week period.

Sample Characteristics. Of the 10 intake cases 2 had more than one reason for referral. One case involved inadequate supervision and gross physical neglect. The other listed gross physical neglect, situational neglect, and emotional neglect as causes for referral. All other cases listed only one reason. For the 10 intake cases there were a total of 13 types of referrals.

Referral Frequency

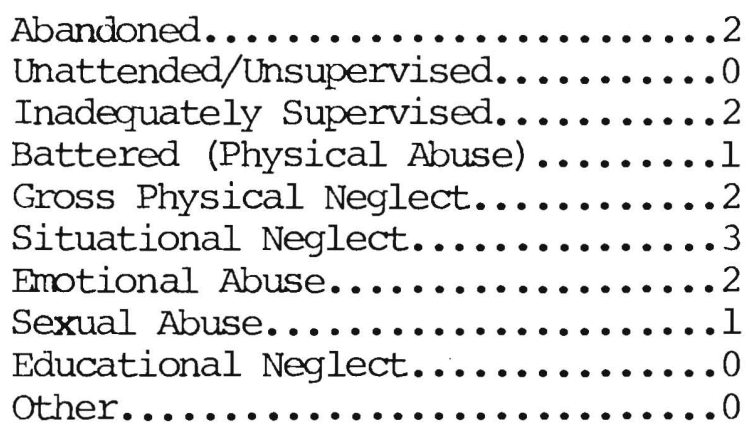

of the 14 possible referral sources there were only 6 that referred. The most frequent source of referral was from the local North Office Intake Unit. 


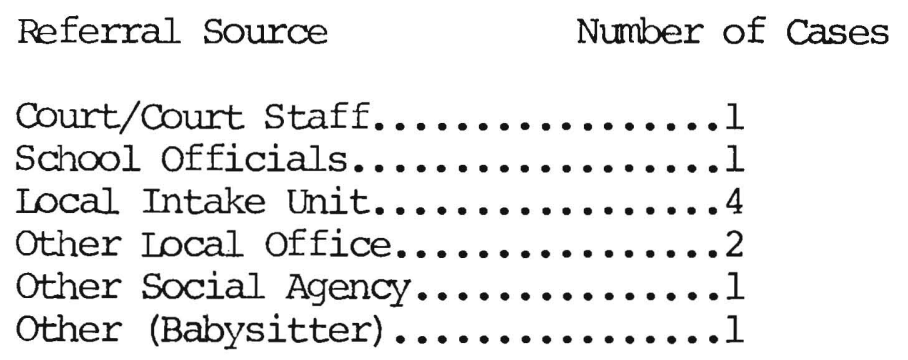

From the 10 intake cases there were a total of 22 children involved. A significant result, as shown in Table I, was in their location at the point of referral as compared with after the twelve-week period. Over half of the children were out of their home inititally, but at the end of twelve weeks only 1 had not been returned home. This reflects the unit's philosophy that children should be returned to their parents whenever possible.

TABLE I

LOCATION OF CHIIDREN BEFORE AND AFTER INTAKE

Location

At Point of At Fnd of

\begin{tabular}{ccccc} 
Referral & Percent & & 12 Weeks & Percen \\
\cline { 1 - 1 } & & $46 \%$ & 21 & $95 \%$ \\
6 & 27 & & 1 & 5 \\
$\frac{6}{22}$ & $\frac{27}{100 \%}$ & $\frac{0}{22}$ & $\frac{0}{100 \%}$
\end{tabular}

Six of the 10 cases had juvenile court involvement during the twelve-week period. In 3 cases court action was not pursued. Wardship and temporary commitment to Children's Services Division were established in the remaining 3 cases by the end of this period. These 3 cases involved a total of 6 children, only 1 of whom was in foster care at the end of twelve weeks. The remaining 5 were in their own hame. There were no cases in which a voluntary agreement was signed by the parents 
for placement of a child.

Analysis of Time and Effort. The Oregon Children's Services Manual sets seven calendar days as the specific criterion for the maximum period of time from the receipt of a report to the initial contact with the family. There were only 2 cases in the sample of intake cases which did not meet this criterion. In one the family could not be located, and in the other it took the worker eight days in which to contact the family. In half of the cases contact was made with the family within 24 hours, as shown in Table II. These 5 cases included 1 physical abuse, I situational neglect, 2 abandonment, and 1 emotional abuse.

\section{TABLE II}

\begin{tabular}{|c|c|}
\hline 1 & 3 \\
\hline 2 & 0 \\
\hline 3 & 1 \\
\hline 4 & 0 \\
\hline 5 & 0 \\
\hline 6 & 2 \\
\hline 7 & 0 \\
\hline 8 & 1 \\
\hline Never & 1 \\
\hline
\end{tabular}

A mean of 17 hours per case were spent on client and collateral contacts over the twelve week period. of these hours 70 percent were spent with clients, and 30 percent with collaterals.

Figure 3 illustrates the distribution of total number of hours per week with clients and collaterals over the twelve-week period for 10 intake cases. The highest hours of contact for both categories was during 
the second week. The sixth week showed a sudden drop, followed by a general decline in hours of contact per week.

\section{Figure 3 Here}

Figure 4 illustrates the variation among workers in hours spent with clients and collaterals.

Figure 4 Here

In two instances the number of hours was affected by external circumstances. Worker $\mathrm{C}$ had one case in which the parent and child left the state during the sixth week. In another case Worker $\mathrm{E}$ was unable to locate the parent in one case after several attempts.

Figure 5 illustrates the difference in distribution of total number of contacts per week with client and collateral over the twelve-week period. Fifty percent of the contacts were with clients, and 50 percent with collaterals.

\section{Figure 5 Here}

In the first two weeks the number of collateral contacts significantly exceeds client contacts, although the duration of these contacts is shorter. During the sixth week, the number of contacts for both categories decline and begin to level out. 


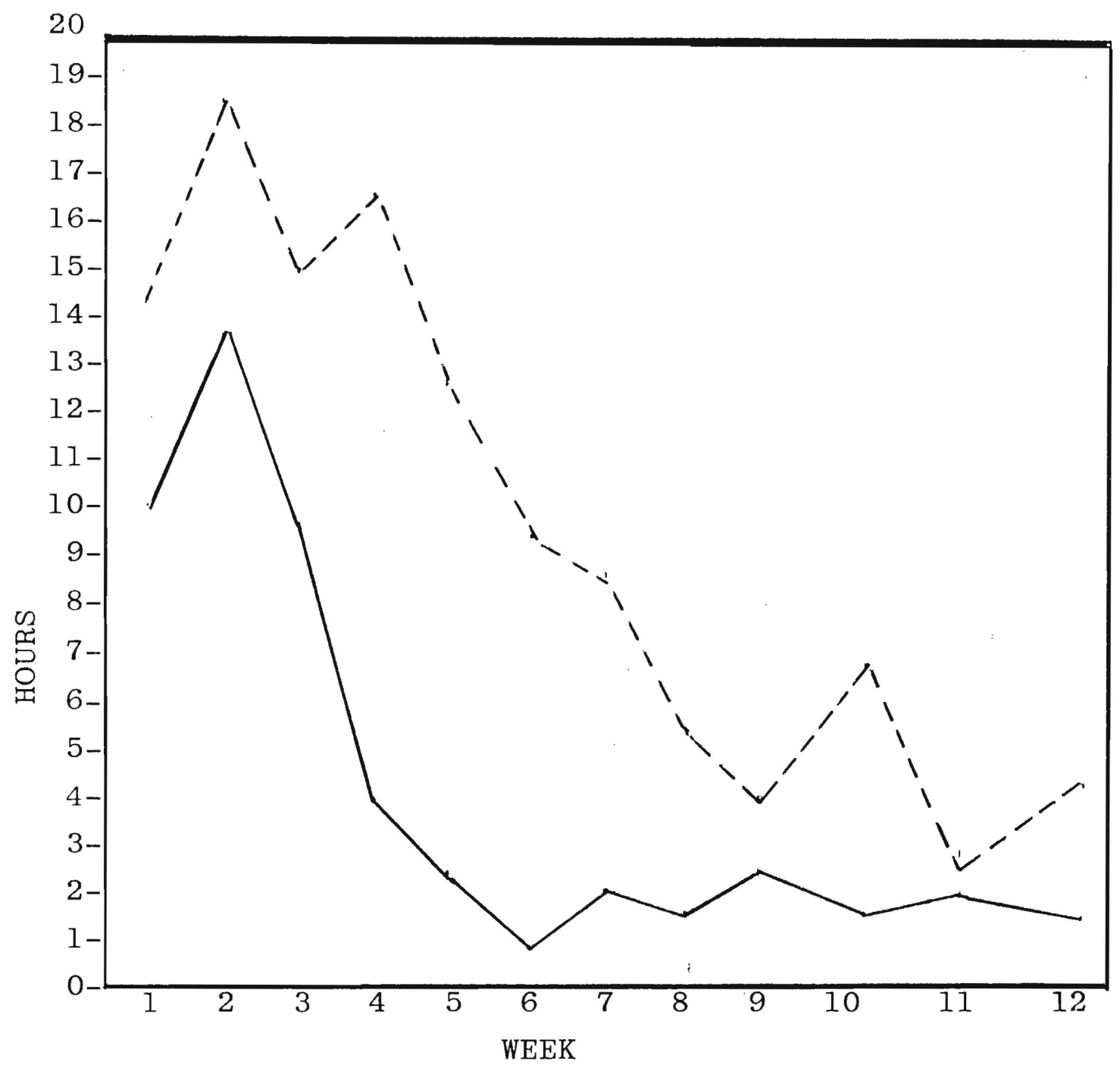

Figure 3. Intake Cases: Total Number of Hours per Week with Clients and Collaterals (10 cases)

-.-- Client Collateral 


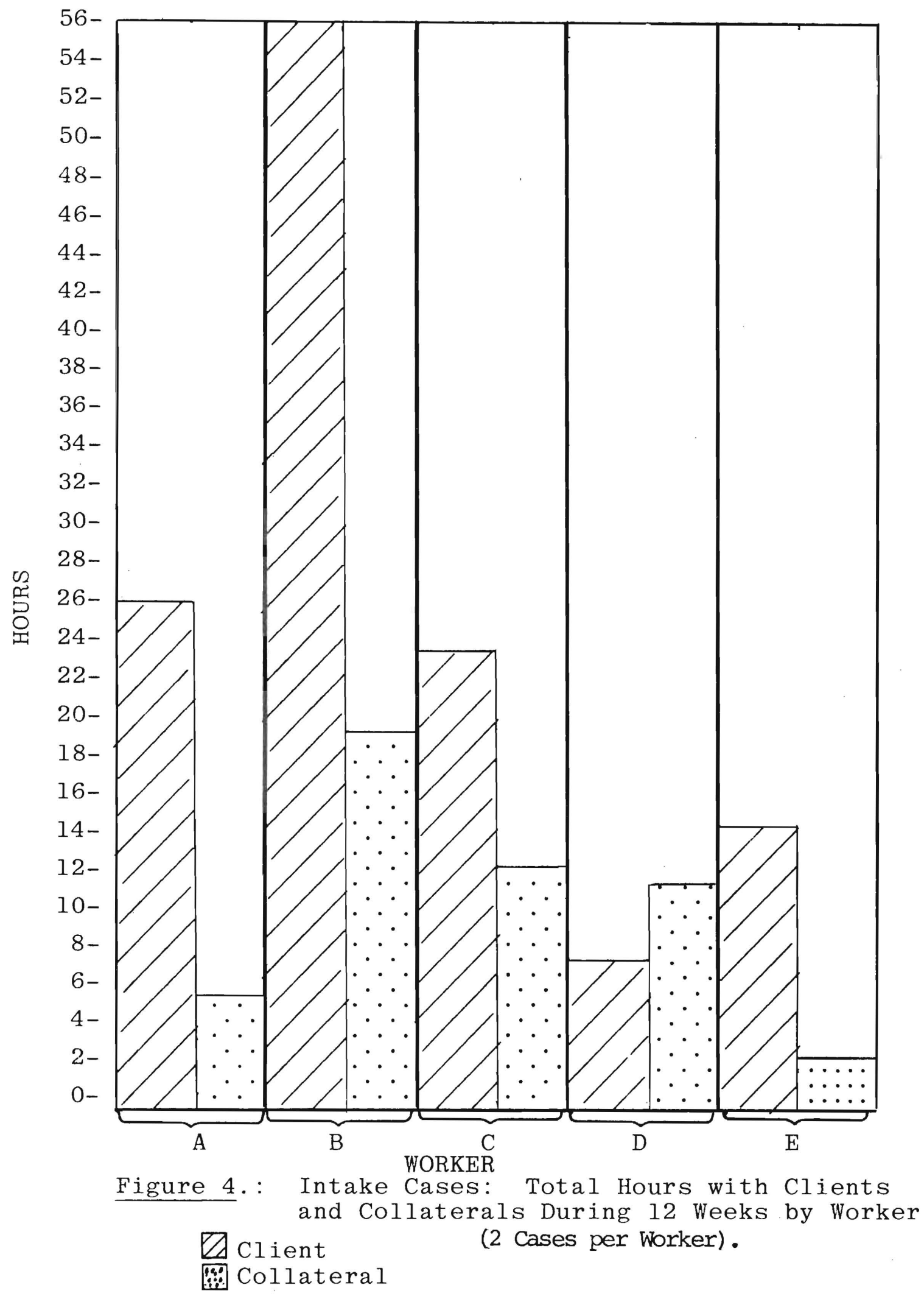




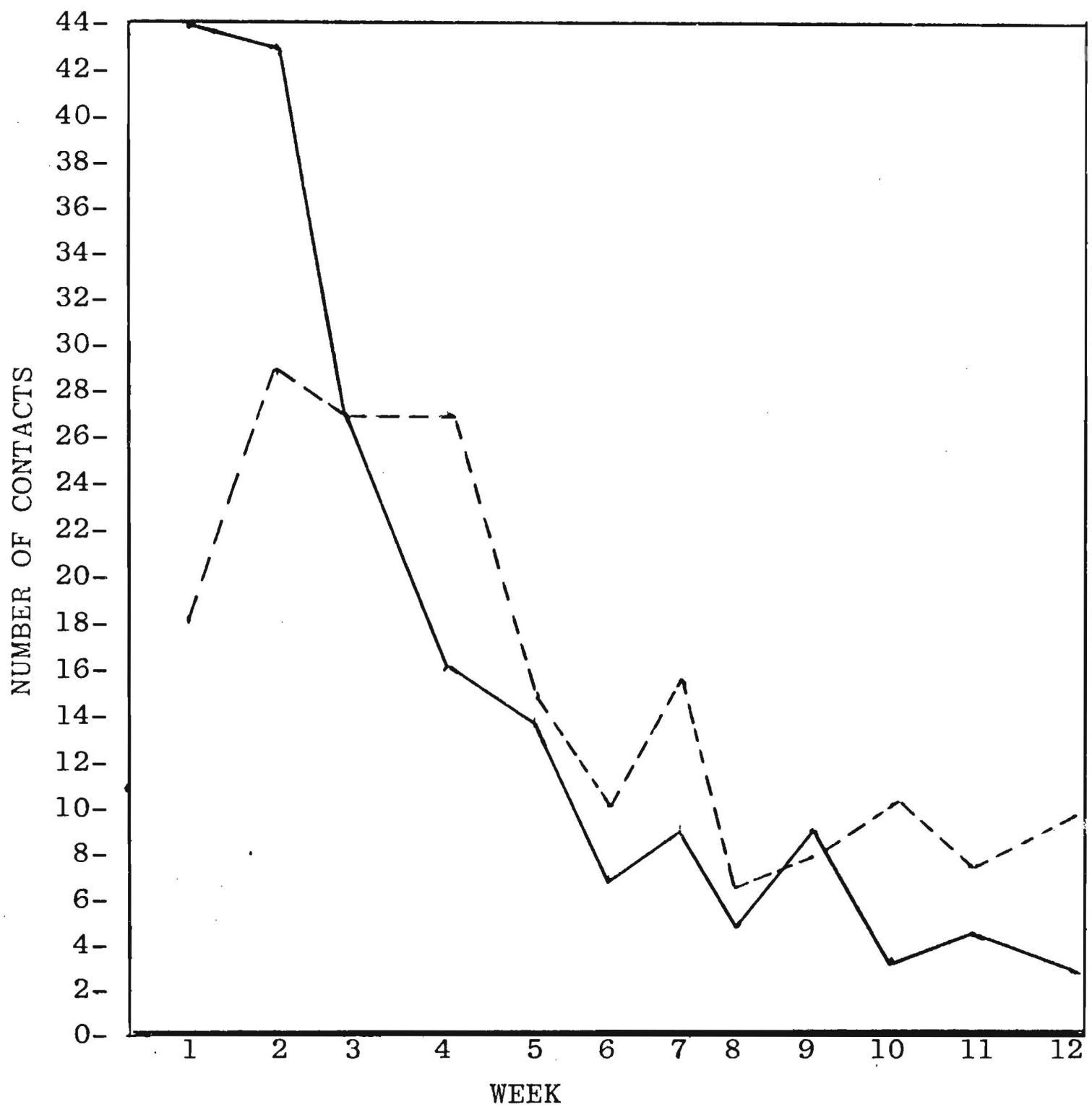

Figure 5. Intake Cases: Number of Contacts per Week with Clients and Collaterals (10 cases)

Client

Collateral 
The mean number of contacts per case over the twelve-week period was 37. The variation among individual workers and the number of client and collateral contacts are shown in Figure 6.

Figure 6 Here

The same factors which affected the total time of workers $\mathrm{C}$ and $\mathrm{E}$ also affected their total number of contacts.

Also involved with client and collateral contacts is the amount of travel time. Over the twelve-week period an average of 3 hours per case were spent traveling to and from contacts.

The final variable to be considered in this analysis of time and effort is paperwork. A distinction was made between paperwork required by Children's Services Division, and that which was related to court involvement. Figure 7 illustrates the distribution of hours spent on each per week over the twelve-week period.

\section{Figure 7 Here}

Time spent on Children's Services Division paperwork remained relatively consistent over the sampled time frame. The court-related paperwork showed a significant increase between the sixth and eighth week. The increase coincides with the decrease in number and hours of client and collateral contacts. 


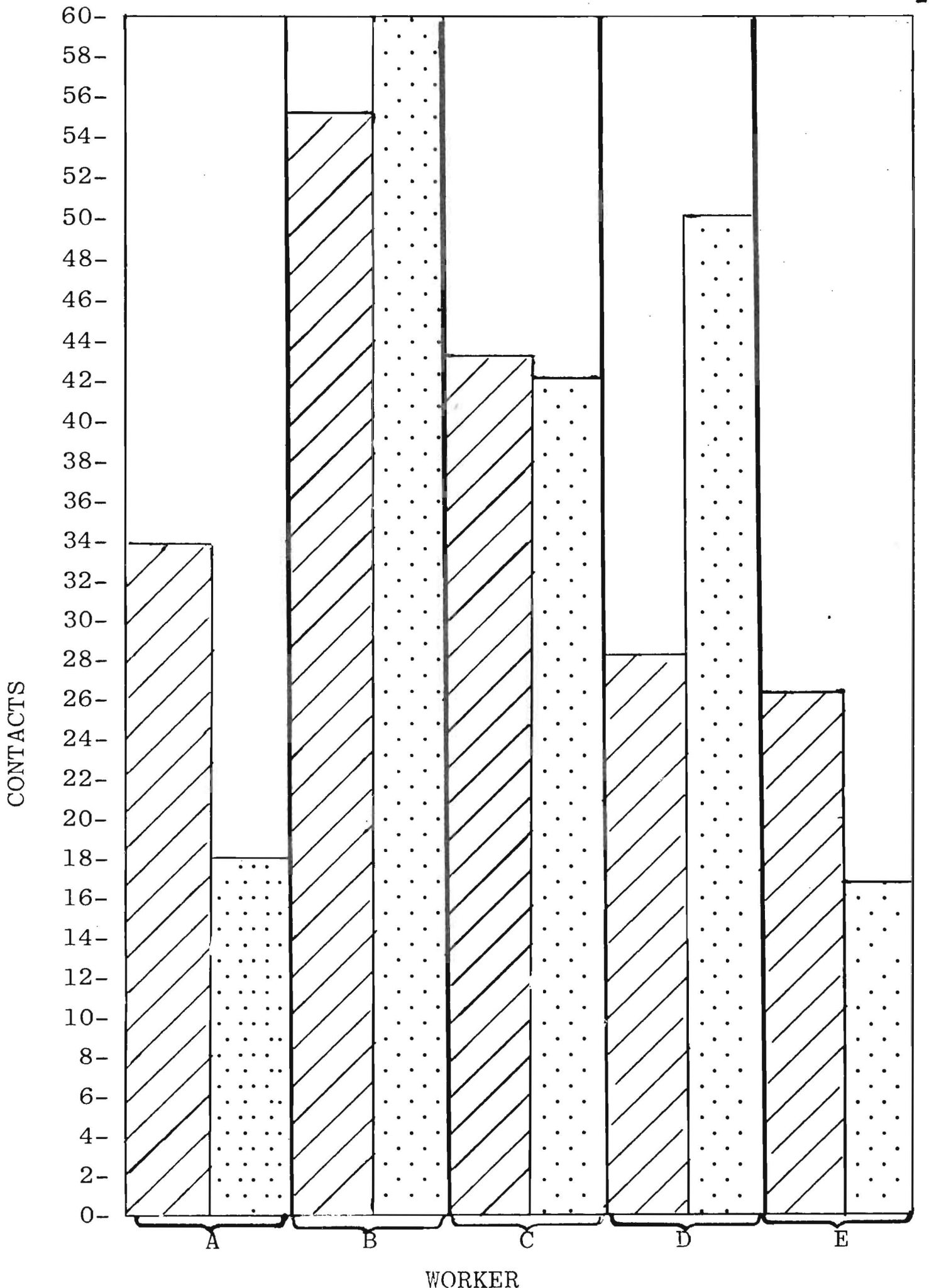

Figure 6. Intake Cases: Total Number of Client and Collateral Contacts During 12 Weeks by Worker (2 Cases per Worker). 


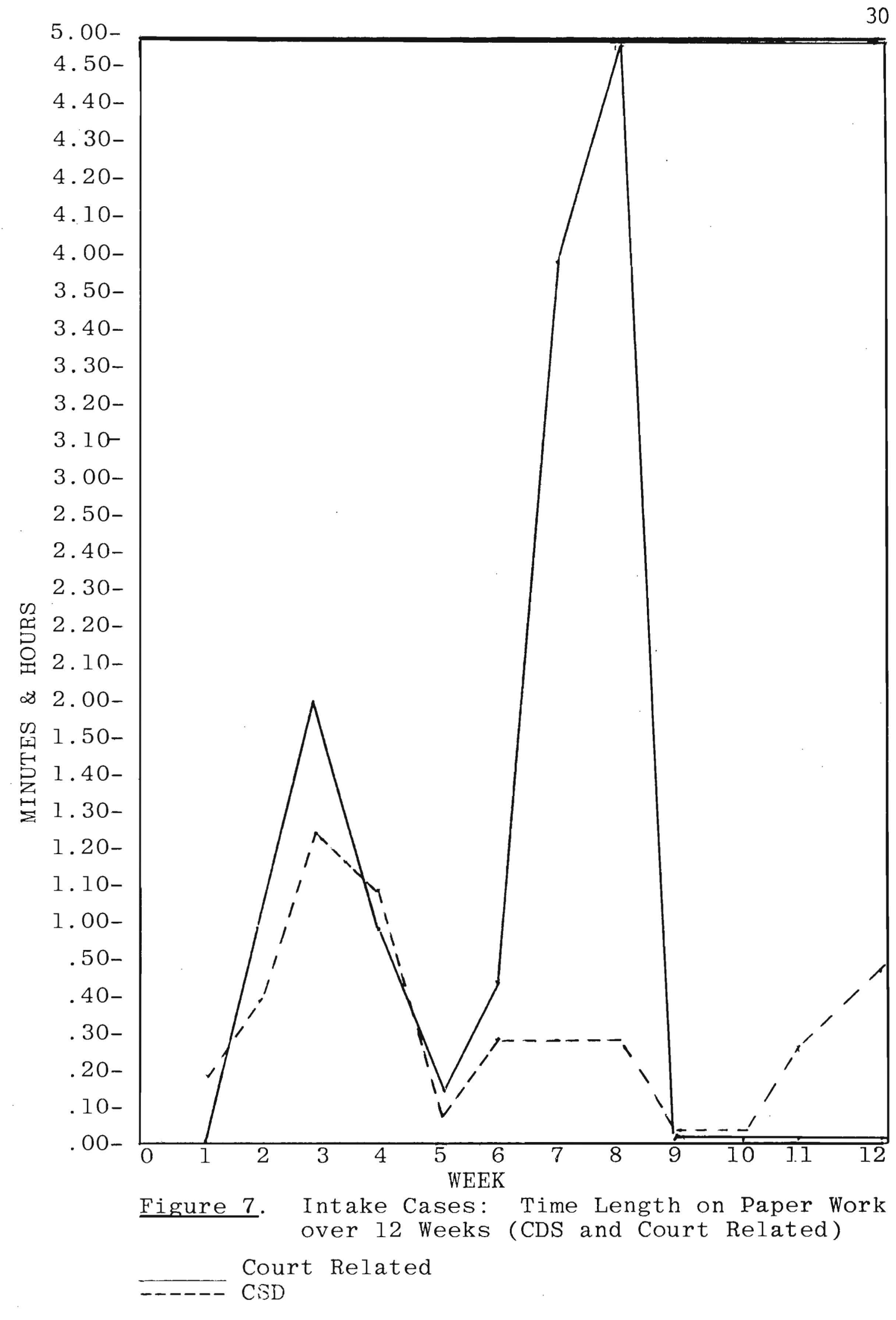


This chapter reports the descriptive findings, and an analysis of a cross-section of activity for 40 ongoing cases which were randomly selected from the unit. The total number of ongoing cases in the unit at the time of sampling was 103. For the five workers the mean number of ongoing cases per worker was approximately 21. This figure does not include the sample of 10 intake cases.

Sample Characteristics. Of the 40 ongoing cases 3 had more than one reason for referral. Two cases involved inadequate supervision and situational neglect. The third case listed unattended/unsupervised and situational neglect. All other cases listed only one reason. The most frequent reason for referral was situational neglect. There were a total of 43 reasons for referral.

Referral Frequency

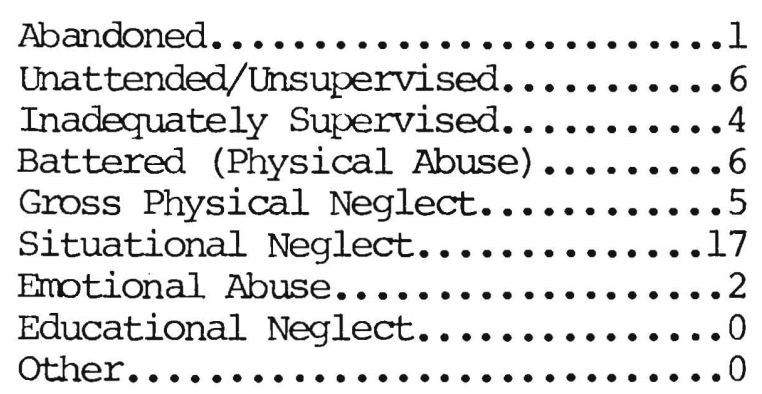

The 40 ongoing cases reflected a wide range of sources of referral. Law enforcement accounted for more than twice as many referrals as any other single referral source. There were 3 cases in which the source 
was listed as other but not explained.

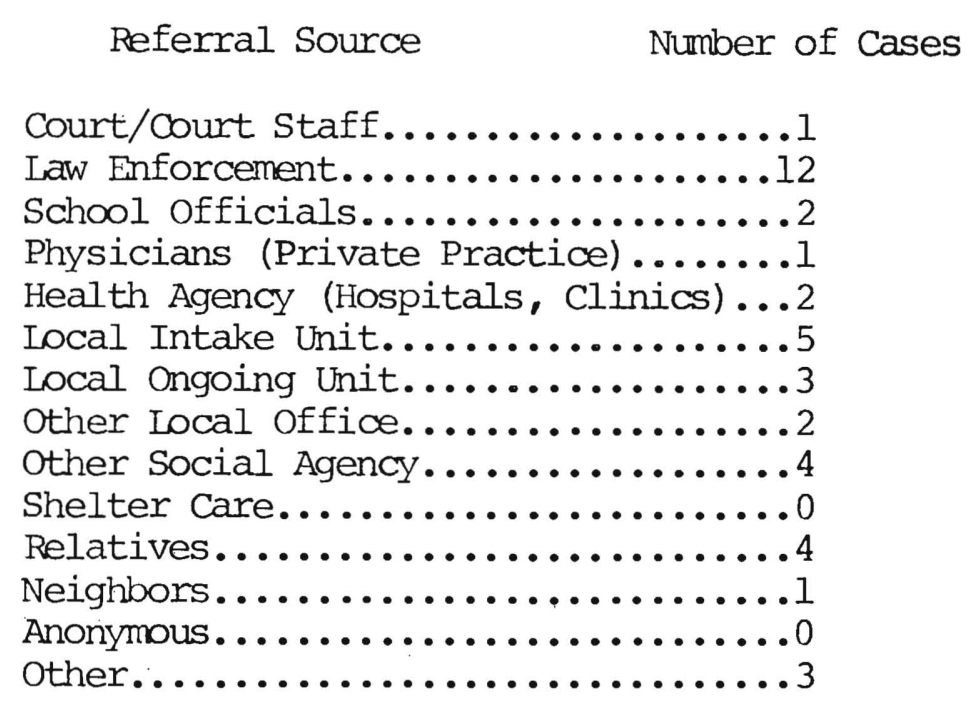

The total number of children represented in the sample was 105. Table III represents the location of these children at the time of sampling. Approximately 84 percent of the children were residing in their own homes.

TABLE III

LOCATION OF CHIIDREN

IN ONGOING CASES

Location

At Home

Foster Care

Other
Number of Children Percent

$\begin{array}{rc}88 & 84 \% \\ 14 & 13 \\ 3 & \frac{3}{100}\end{array}$

The three cases listed under "Other" involved 1 child in a group home, 1 in shelter care, and 1 living with grandparents.

Children's Services Division had been given temporary comitment by the juvenile court on 27 percent of the children, and of these 57 percent were with their parent(s) under the supervision of Child Protective 
Services, and 1 child was with grandparents.

Examining the same data in terms of the number of cases involved gives another perspective. Table IV illustrates the location of the children and the number of cases involved. In 80 percent of the cases all the children were at home.

TABIE IV

LOCATION OF CHILDREN BY CASE

IN ONGOING SAMPIE

Location

All Children at Home Some Children at Home/ Some Children placed

All Children placed outside of Home
Number of Cases $\quad \underline{\text { Percent }}$

32

$80 \%$

3

7

$\frac{5}{40} \quad \frac{13}{1008}$

For 30 percent of the families, of the ongoing cases Children's Services Division had been given temporary commitment by the juvenile court of either some or all of the children.

The sample cases reflect a wide range of time that the workers in the Child Protective Service unit have been involved with these ongoing cases. The median time in service was one year. In some instances cases were brought into the specialized unit by the individual worker from a previous caseload. This information does not necessarily indicate the length of time that a case has had involvement with Children's Services Division prior to the worker being assigned to the case. Table $\mathrm{V}$ shows the distribution of the frequency of cases for each. 
TABLE V

DURATION OF ONGOING CASE INVOLVEMENT

Time Period

0-6 months

7-12 months

13-18 months

19-24 months

25-30 months

31-36 months

over 37 months

$\begin{array}{cc}\text { Frequency of cases } & \frac{\text { Percent }}{7} \\ 13 & 18 \% \\ 12 & 33 \\ 1 & 30 \\ 4 & 2 \\ 0 & 10 \\ \frac{3}{40} & 0 \\ & \frac{7}{100 \%}\end{array}$

Analysis of Time and Effort. To demonstrate a cross-section of activity from the workers' ongoing caseloads the total number of contacts for clients and collaterals were combined, as was the amount of time. This differs from the analysis of the intake cases which considered client and collateral contacts separately.

For each worker there was a mean of 2.3 contacts for each case per week. A mean time of 30 minutes was required per contact. Table VI illustrates the distribution of these data by worker.

TABLE VI

CONTACTS AND TIME BY WORKER

$\begin{array}{ccccc}\text { Worker } & \begin{array}{c}\text { Total } \\ \text { Contacts }\end{array} & \begin{array}{c}\text { Mean } \\ \text { Contact } \\ \text { per Case }\end{array} & \begin{array}{c}\text { Mean Time } \\ \text { per Contact }\end{array} \\ \text { A } & 17 & & 2.1 & 35 \text { minutes } \\ \text { B } & 10 & 1.3 & 62 \text { minutes } \\ \text { C } & 28 & 3.5 & 16 \text { minutes } \\ \text { D } & 13 & 1.6 & 17 \text { minutes } \\ \text { E } & 24 & 3.0 & 19 \text { minutes }\end{array}$

${ }^{\star} 8$ cases per worker. 
Worker B had the least number of contacts, but spent the most time per contact, whereas the worker with the highest number of contacts spent the least amount of time per contact.

A different perspective is gained by examining the time spent per case by each worker during one week. The mean amount of time spent on each case per week was 55 minutes. Table VII shows the mean time each worker spent on a case per week in client and collateral contacts.

TABLE VII

TOTAL TIME PER CASE PER WEEK

(COI.TATERAL AND CLTENT

CONTACTS)

$\begin{array}{cccc}\text { Worker } & \begin{array}{c}\text { Total Time for } 4 \\ \text { weeks on } 8 \text { cases }\end{array} & & \begin{array}{c}\text { Time per case } \\ \text { per week }\end{array} \\ \text { A } & & & \\ \text { B } & 690 \text { minutes } & & 74 \text { minutes } \\ \text { C } & 435 \text { minutes } & & 78 \text { minutes } \\ \text { D } & 215 \text { minutes } & & 54 \text { minutes } \\ \text { E } & 340 \text { minutes } & & 27 \text { minutes } \\ & & 43 \text { minutes }\end{array}$

Combining the time spent on paperwork and in traveling to and from contacts gives another measure of activity for the ongoing cases. The mean amount of time spent on each ongoing case for these tasks was 1.5 hours.

Summary. In this study we did not attempt to account for all of a worker's time, but simply to determine 1) how much time goes into an intake case and how this varies over time during the twelve-week period of intake; and 2) how much time typically goes into service to clients in ongoing cases, specifically the number of contacts and time per contact. However, it does provide perspective to an estimate of caseload 
demand for time. Ongoing cases alone consume an estimated average of 24 hours per week for an average caseload (2.3 contacts x 30 minutes $\times 21$ ongoing cases). This does not include the time required for intake cases which workers also handle. As we saw, intake time ranges wider, with the first few weeks involving three times the effort required later. This points up the need to allow sufficient time for an adequate response to intake cases. The outcome results do support that this kind of effort helps to maintain children in their own homes. 
CHAPTER VII

\section{CONCLUSIONS AND SUMMARY}

The study examined the effort and activity involved in services to both intake and ongoing cases, providing a quantitative and descriptive picture of a protective service caseload. In order to achieve this we related data regarding time and effort with knowledge of the processes and decisions involved.

The results can best be summarized in the context of the three program phases discussed in Chapter I: assessment, development of a social service plan, and provision of ongoing services. These are considered primary processes in the service delivery plan. In the following discussion the activity involved in the intake cases will be related to the assessment phase and development of a social service plan. The ongoing caseload will be examined in terms of the provision of ongoing services. Incorporated is a discussion of decision-making.

The intake cases show that the activity level is highest during the first six weeks which includes the assessment phase and development of the service plan. During this period the worker has three times greater contact with clients than at any other time. Similarly, there is more contact with collateral sources. This would support Boehm's (1964) contention that protective services effort call for a strong linkage between protective service and other community and welfare services. The nature of these contacts during this period center around: 1) evaluation of the complaint; 2) exploration of community resources; 
and 3) coordination of community services. During this period the first two primary decision points of 1) appropriateness of the referral and its validity, and 2) determining if an emergency exist, are reached. The service plan is also formulated.

As the activity level decreases on the intake cases after the first six weeks, there a transition is made from intake to provision of ongoing services. Beginning in the sixth week the number and hours of contact with the intake cases decrease and begin to approach the mean number and hours of contact as in the ongoing cases, which was 2.3 contacts of 30 minutes each.

It is in the provision of ongoing services that the social worker implements the service plan through the use of skills identified in Chapter II. The goal is to alleviate or reduce the problem which was the basis for the referral to protective services. During this process the worker must continually reevaluate the service plan to determine if the stated treatment goals are being achieved. The data on time and effort do not by themselves provide the basis for evaluating quality of service, but do illustrate that continual contact is made with the family.

There is other evidence, however, that the services may have been appropriate. A recurring observation made was that services were directed toward maintaining children in their own home. This is demonstrated by continual client contact both in intake and ongoing cases. A more dramatic measure of this philosophy was that 95 percent of the children were residing in their own homes by the end of the twelve-week intake phase. Further, 84 percent of children in the ongoing protective services cases reside in their own homes. 
The unit's performance is consistent with the goals as stated by the Child Welfare Ieague, that: 1) unnecessary separation of the child from his parents should be prevented; and 2) whatever may be of value for the child in his relationship with his parents should be conserved. (CWLA, 1969) The first statement is true with one important qualification. In the process by which the cases come to the unit, children have sometimes already entered shelter care as a response to an emergency. By the end of the twelve weeks, however, most are returned home. The data suggests, as does DeFrancis (1973), that more intense service to families referred to protective services will inevitably reduce the number of children who must be ultimately separated from their homes. With the prevention of placement of children into foster care there is a pragmatic saving. It is far less costly to pay the salary of a protective service worker, who may prevent unnecessary placements, for a time limited period than to pay the cost of continued foster care. To underscore this, DeFrancis (1975) notes that the national average cost per child per year in foster care is about $\$ 2,000$.

One of the prime requisites for provision of adequate child protective services is that caseload levels be between 20 and 25 active cases per worker. (American Humane Association, 1967) During the period of data collection, the mean caseload size for each worker in the unit was 23 cases. The unit's practice is in keeping with the recommendation. The need for controlled caseload size is further substantiated by the time and effort expended during the first six weeks of an intake case. The low caseload size facilitates an early response to referrals. In 50 percent of the intake cases contact was made with the client with- 
in 24 hours. Protective services, by nature, involve crisis situations. Small caseloads enable the workers to intervene early for the protection of the child and welfare of the family.

There were two areas in which the performance of the unit was not consistent with the standards described in the Program Service Manual for Protective Services. First, the unit serves some children in ongoing foster care which the manual says should be transferred to another program service classification and unit. Secondly, the unit serves long-term cases to a major extent, again contrary to manual guidelines. on both issues the unit believes their service is appropriate, and that the policy should be changed.

Under policies and procedures one of the reasons listed for termination (closing or transferring) of protective service cases is:

The children have been removed from their home by voluntary consent of the parents or by court order. (Oregon CSD Program Service Manual, November 1973)

Of all the cases sampled, only 14 percent of the children were not residing with their parents. These cases had not been transferred, and were being followed for services in the specialized Child Protective Service unit.

In another section of the Program Service Manual a note is made that

Protective Services should not be provided for longer than six (6) months unless there are extenuating circumstances which must be documented in the case record. The family should have made sufficient progress in six (6) months so that the case can either be closed or services pro- 
vided under another program service classification. If this does not occur, and the parents continue to abuse/neglect their children, alternative planning must be considered. (Oregon CSD Program Service Manual, November 1973)

In the ongoing sample, 83 percent of the cases had been in the unit over six months.

How should one view this discrepancy between the stated standards and the unit's actual performance? Is the unit violating valid or desirable standards, or should the standards be reevaluated? Although the policy has a desirable objective, namely to give a time-limited focus to services, the investigators are inclined to agree with the unit's belief that

1) adherence to the guidelines would arbitrarily disrupt the continuity of needed services;

2) the clients served require continued service of the kind provided. 


\section{REFERENCES}

American Humane Association. Child Protective Services: A National Survey. Denver, Colorado: The American Humane Association, Children's Division, 1967.

Beck, Bertram M. "Protective Casework: Revitalized, Part I." Child Welfare, 1955, $34(9), 1-7$.

- "Protective Casework: Revitalized, Part II." Child Welfare, 1955, $34(10), 16-20$.

Boehm, Bernice. "The Community and the Social Agency Define Neglect." Child Welfare, 1964, 43(11), 454-464.

- "Protective Services for Neglected Children." In

Social Work Practice. New York: Columbia University Press, 1967.

Brieland, Donald. "Protective Services and Child Abuse: Implications for Public Child Welfare." Social Service Review, 1966, 40(4), 369-377.

Child Welfare League of America. Standards for Child Protective Service. New York: Child Welfare League of America, 4th Printing, 1969.

Davoren, Elizabeth. "A Social Worker's View: Working With Abusive Parents." Children Today, 1975, 4(3), 2,38-43.

DeFrancis, Vincent. "Testimony Before Senate Subcomittee on Children and Youth." Speaking Out for Child Protection. Denver, Colorado: The American Humane Association, Children's Division, 1973.

and Lucht, Carroll. Child Abuse Iegislation in the 1970's. (Rev. ed.) Denver, Colorado: The American Humane Association, Children's Division, 1974.

- "Child Protection: A Comprehensive, coordinated Process." The Fourth National Symposium on Child Abuse. Denver, Colorado: The American Humane Association, Children's Division, 1975.

Gordon, Henrietta L. "Protective Services for Children." Child Welfare League of America Bulletin, 1946, 25(5), 1-6. 
Health Resources Administration. Case Studies of Ten Child Abuse and Neglect Demonstration Projects: The First Year of Federal Funding. (An Evaluation of the Office of Child Development/ Social Rehabilitation Services Joint Demonstration Program in Child Abuse and Neglect.) Berkeley, California: Berkeley Planning Associates, September 1975.

Helfer, Ray and Kempe, Henry (Eds.) The Battered Child (2nd ed.) Chicago, Illinois: The University of Chicago Press, 1974.

Hoshino, George and Yoder, George. "Administrative Direction in the Implementation of Child Abuse Legislation." Child Welfare, 1973, $42(7), 414-424$.

Jeter, Helen R. Children, Problems, and Services in Child Welfare Programs. Washington, D. C.: Government Printing Office, 1963. (Children's Bureau Publication, No. 403).

Oregon, State of, Department of Human Resources, Children's Services Division. Protective Services Program Manual, Vol. 4, November $19 \overline{73 .}$

Scherer, Lorena. "Protective Casework Services." Children, 1956, 3(1), 27-31. 


\section{INSTRUCTIONS FOR COMPLETION \\ OF EFFORT FORM "B"}

\section{PREFACE}

This form is to serve as a means for the collection of essential data which will be used in the Descriptive Analysis of the Protective Service Unit.

WORKER'S NAME: Self-explanatory

$\underline{\operatorname{DATE}(S)}:$ Date (s) covered by form

\section{CLIENT'S NAME: Family Name}

Number of Children: Number of children under the age of 18 living In the home, to include those children outside of the home who are served by the CSD Protective Service Unit.

Type of Referral: Refer to attached code Sheet. Enter the number(s) which corresponds with the type of referral.

Opening Code: Refer to attached code Sheet. Enter the number which corresponds with the Opening code.

Date of Referral: Date referral was received by CSD Protective Service Unit.

Date of First Contact: Date of first personal contact (phone, office, field) with client.

Consent for Temporary Placement: Date Voluntary Consent Form for temporary placement was signed.

Court Petition: Date petition was filed with Juvenile Court. Wardship: Date Court Wardship was established.

Temporary Cormitment: Date temporary commitment was established.

Anticipated Closure: Approximate anticipated closure date for case.

Termination Code: Refer to attached code Sheet. Fnter the number which corresponds with the reason for case closure. 
Formal Hearing: Date of formal hearing with the Juvenile court.

CLIENT CONTACIS: Those members of the immediate family involved in Protective Service referral.

Office: In-office interview with a client. This includes dates and time for the interview. Enter date and time as follows: Date/Time.

Field: out-of-office interview with a client. This includes dates and time for the interview, and does not include travel time. Enter date and time as follows: Date/Time.

Travel Time: Time spent traveling to and from interview and/or attempts to contact client.

Telephone: Telephone contact with client. This includes dates and time. Enter date and time as follows: Date/Time.

CSD Paperwork: Time spent doing paperwork required by CSD, i.e., forms, letters, reports, etc. (other than court).

COLIATERAL CONTACIS: Those other than client contacts including referral source, staffings, court, financial, etc.

Office: In-office interview with a collateral. This includes dates and time for the interview. Enter date and time as follows: Date/Time. Indicate who was contacted.

Field: Out-of-office interview with a collateral. This includes dates and time for the interview and does not include travel time. Enter date and time as follows: Date/Time. Indicate who was contacted.

Travel Time: Time spent traveling to and from interview and/or attenpts to contact collateral.

Telephone: Phone contact with collateral. This includes dates and time. Finter date and time as follows: Date/Time. Indicate who was contacted.

Court Related Paperwork: Time spent doing paperwork required by Juvenile court as it pertains to the case, i.e., letters, forms, reports, etc. 


\section{CODES: EFFORT FORM "B"}

TYPE OF REFERRAL,

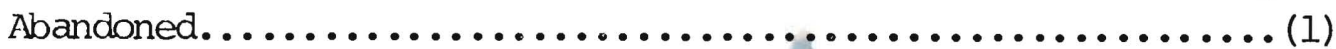

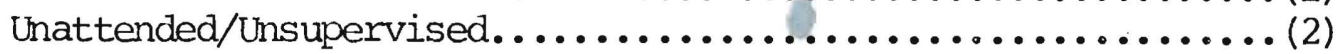

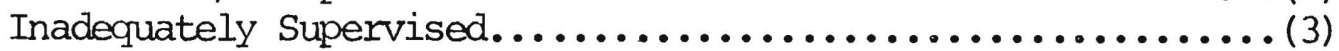

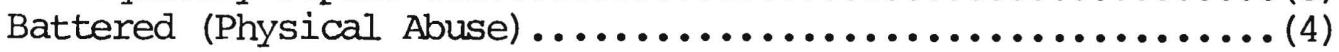

Gross Physical Neglect........................... (5)

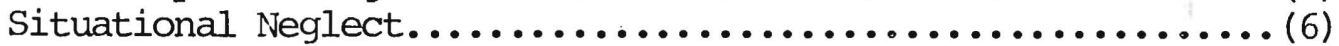

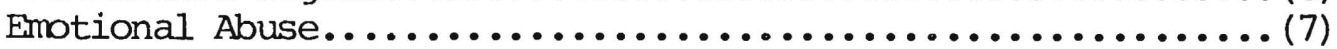

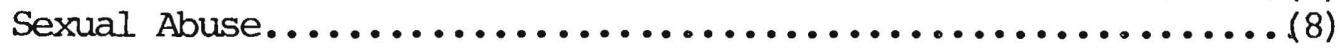

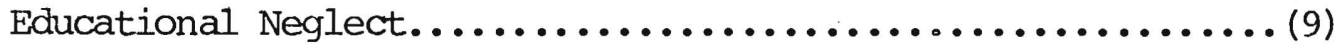

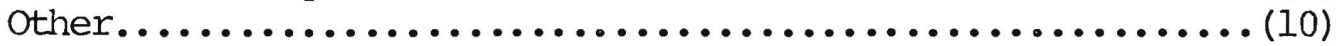

OPENING CODE

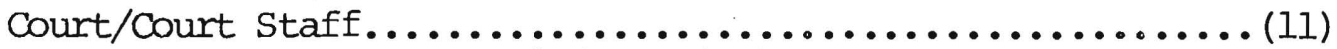

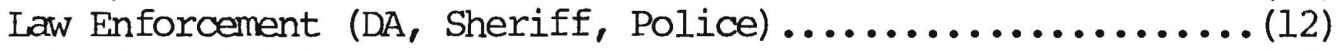

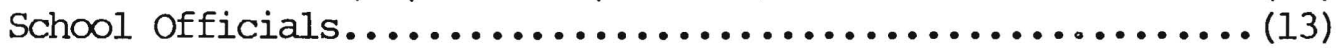

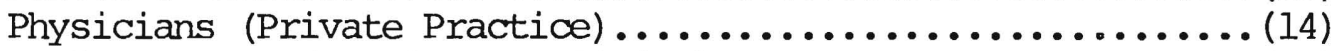

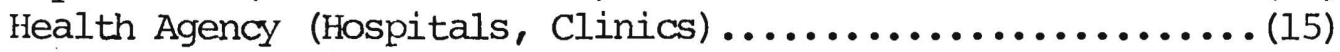

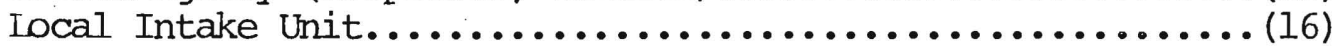

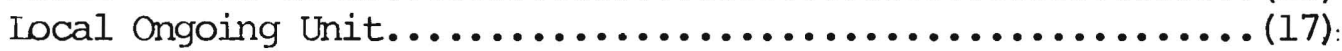

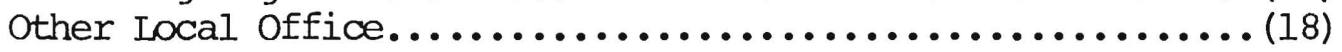

Other Social Agency ................................. (19)

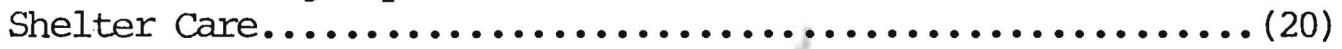

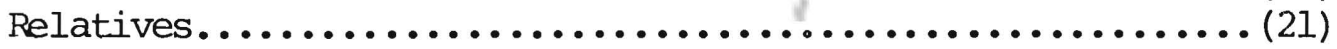

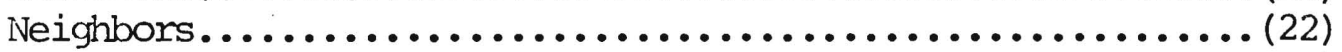

Anonymous . . . . . . . . . . . . . . . . . . . . . . . . . . . . . . (23)

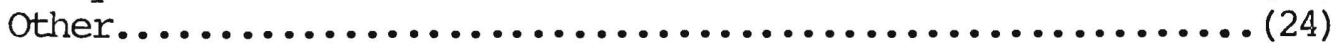

\section{TERMTNATION CODE}

No Abuse/Neglect Exists............................... (25)

Family Functioning with no Further Need for Protective

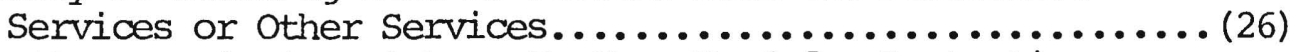

Family Functioning with no Further Need for Protective

Services: Referred to Other Unit.................... (27)

Family Functioning with no Further Need for Protective

Services: Referred to another Agency/Professional for

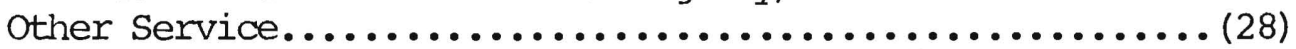

Child(ren) placed out of home, Long-Term: Referred to ongoing Children's Worker.......................... (29)

Family Moved out of Local Office Jurisdiction: Case

Transferred.................................. (30)

Family Moved - Cannot be Located...................... (31)

Family Refused to Cooperate: Referral to Juvenile Court

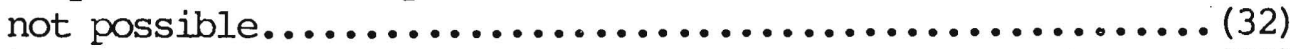

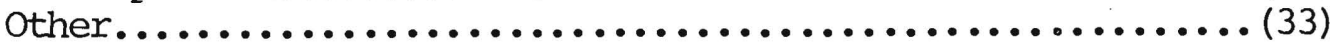


TYPES OF REFERRAIS DEFTNED

(1) Abandoned: A child is considered to be abandoned when the parents have indicated their intent to no longer provide care for the child.

(2) Unattended/Unsupervised: Unattended/unsupervised children are those who are alone for extended periods of time or whose whereabouts are unknown by the parents for extended periods of time. This classification differs from abandonment in that the parents intend to resume their care of the child.

(3) Inadequately Supervised: Supervision is inadequate in cases where the caretaker with whom the child is left does not possess the requisite skills for supervising or when the child is exposed to dangerous items or hazardous conditions in the home.

(4) Battered (Physical Abuse): The child has sustained physical damage, such as bruises, lacerations, fractures, or burns as a result of a nonaccidental physical act or acts.

(5) Gross Physical Neglect: The child has sustained physical or material deprivation, such as not being fed, clothed or bathed, which sometimes results in a physical state of ill health. Adequate medical care may be lacking.

(6) Situational Neglect: Situation where a child receives minimum care and the parent(s) is known or suspected of having emotional problems and/or illness such as alcoholism, drug addiction, mental illness, etc.

(7) Emotional Abuse: The child has sustained emotional damage as shown by his behavior or is endangered as a result of various acts, such as being told repeatedly he is not "good" or by observing a parent or other child abused.

(8) Sexual Abuse: The following are examples of sexual abuse: rape, camal knowledge; seduction; indecent liberties; exposure; incest; sodomy; solicitation; molestation.

(9) Educational Neglect: Situation where the parent(s) refuse to send or allow their child to attend school.

\section{(10) Other:}

Any referral not covered by the above. Please make an explanation in the area for comments on Project Effort Form - B. 


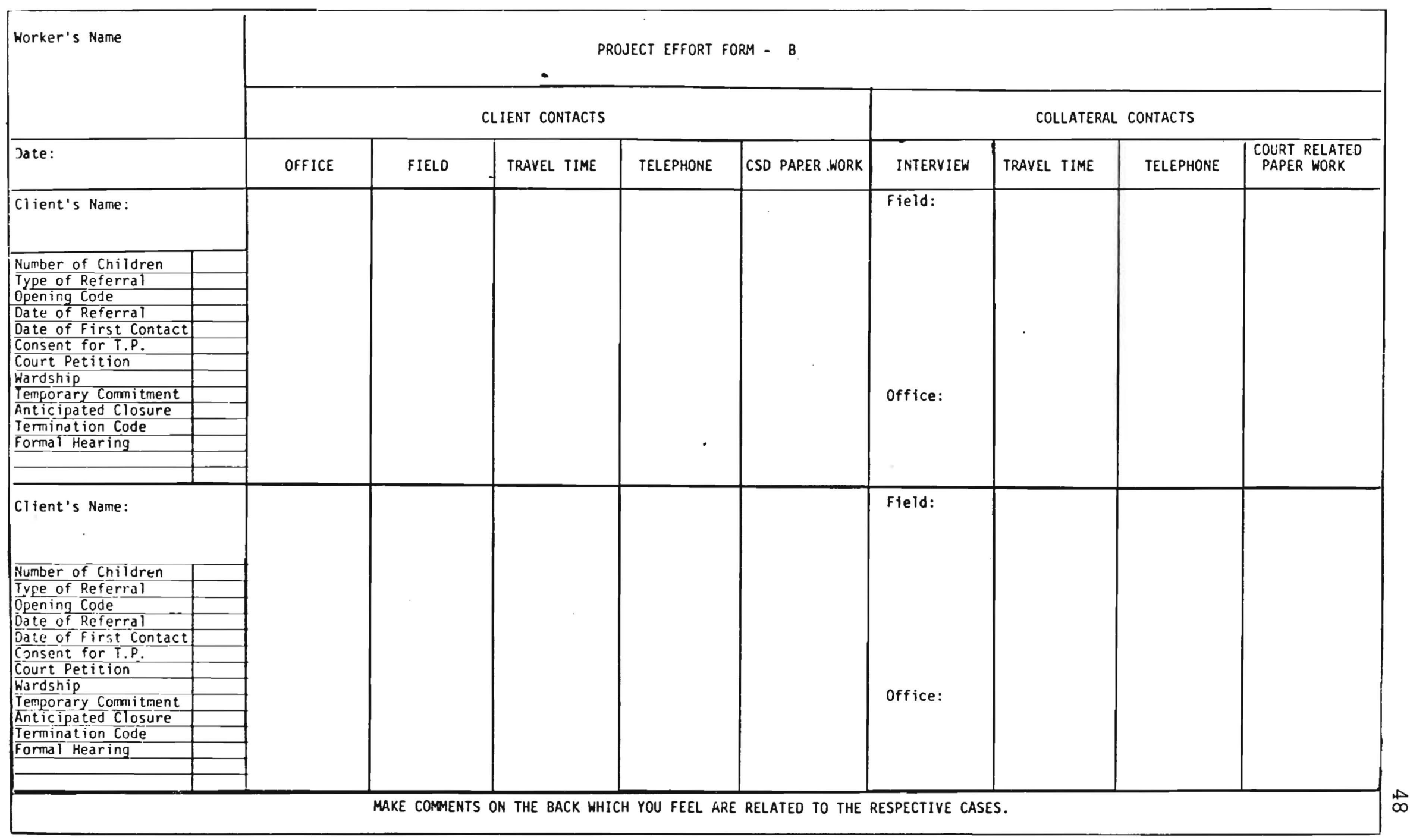

